\title{
إبكالية الاسلوب والأسلوبية في التشكيل الفني
}

أ.م.د. علي مهدي ماجد/ كلية الفنون الجميلة/ جامعة بابل

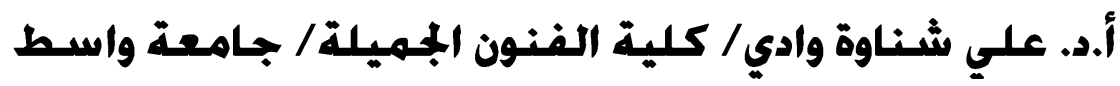

يدرس البحث (إثكالية الاسلوب والأسلوبية في التشكيل الفني) في محاولة لتقصي الخواص العملية في أسـاليب التثكيل الفني، بكل مـا

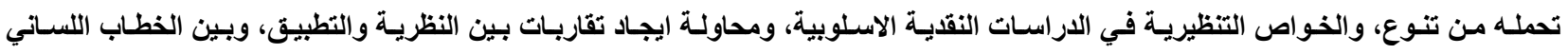

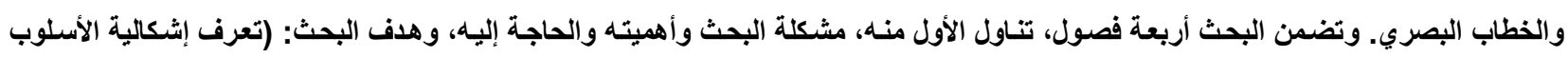
والاسلوبية في التثكيل الفني)، وتناول حدود البحث، وتعريف أهم المصطلحات، واشتمل الفصل الثاني، الجانب النظري المتمثل بدراسـة الاسلوبية والأسلوب في الدراسات النقدية، فيما تناول الفصل الثالث، الفصل التحليلي المتمثل اشكالية الأسلوب في التشكيل الفني، وانتهى البحث باتبكل بالفصل الرابع الأي تناول نتائج البحث واستتتاجاته و التوصيات و المقترحات.

الكلمات المفتاحية: (إشكالية - الأسلوب - الاسلوبية - التشكيل القني)

\section{Problematic Of Style And Stylistic In The Artistic Forming}

Assist. Prof .Dr . Ali Mahdi majid

University of Babylon -

college of fine arte

d.ali.mahdi॰•@gmail.com pro. Dr. Ali shnawa wadi

University of Babylon -

college of Fine Arts

mohammedshnawa11@gmail.com

\section{Abstract:}

The current research tackles with ( Problematic Of Style And Stylistic In The Artistic Forming) as an attempt to investigate the practical characteristics in the styles of artistic forming, with all it's variety, theoretical characteristics in critic and stylistic studies and an attempt to finding out approaches between theory and application and between linguistic and optical speech.

The research includes four chapters, first one dealt with the problem of research, importance and necessity for such research, the goal of research which is : ( Knowing the Problematic Of Style And Stylistic In The Artistic Forming), limits of research, defining most important terms, while second chapter includes the theoretical side represented by studying problematic and style in the critic studies, while the third chapter (Analytical chapter) dealt with problematic of style in artistic forming, finally, the research was ended by the fourth chapter that dealt with results ,conclusions, recommendations and suggestions of research.

Key words: Problematic, style, stylistic and artistic forming.

\section{النصل الأول}

أولاً: مشكلة البحث:

من نظرة شاملة للتاريخ المعرفي البشري، نستتبط مديات من الصـراع والحر الك الدائب في مجمل المعارف و العلـوم و العقائد، التي لا يكـاد يجمعها جـامع او يوحدها فكر، الأمـر الذي إنعكس على صـيغ التعـاطي مـع الحيـاة و أساليب العيش و أنماط السلوك اليومي الذي يعزز ديمومة الحياة، هذا التنوع الذي وصل إلى حد التقاطع، دعى الفكر إلى الخوض في ثنائيات متعارضة، ترسم التوجهات العامة لذلك التتوع، تمثلت بـالروحي و المـادي، الثابت و المتغير، النسبي و المطلق، الذاتي والموضـوعي، الحسـي والحدسي و غير هـا، إزاء ذلك لـم يقدم الفكر حلـولاً، بـل عمق فجوة 
الاختلاف، وتتوعت الآر اءو النظريـات والايدولوجيات، لاسبما في الفكر المعاصـر الذي وسم بالتشكيك والتشتت و التشظي.

إن عملية إطلاق مفهوم عام للأسلوب، يعينتا على مواجهة التنوع، كما يتطلب اتخـاذ موقف يحايث المحتوى

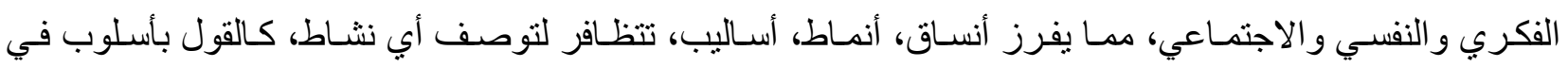
العمل، أو أسلوب في الكلام، أو أسلوب في الحياة، ومنها أسلوب في التعبير الفني، ليكثف في الاسـاليب مـا يمثل خصوصية أفراد او خصوصية مجتمع او عصر. وحين نتقصى الأسلوب ببعده الخـاص، في المجال الابداعي، نكون

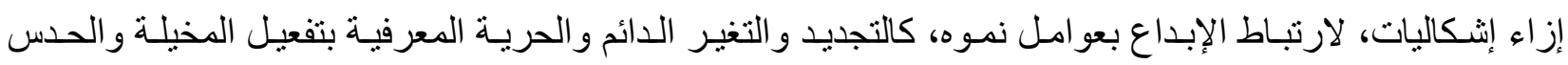
و اللعبب الحـر. فضـلاً عن التجاذبـات الفكريـة و الاجتماعيـة والنفسية والجماليـة التـي تتفاعل معهـا العمليـة الابداعيـة ومنتجيها من شعر اء وفنانين الذين لهم رؤياهم وآلياتهم وتقنياتهم في تشكيل أسلوبهم، وأن التمايز في الأسلوب يمكن أن نلحظه في الاتجاه الواحد أو بين الفنان ونفسه عبر الزمن.

ان الاشكالية الاسلوبية قد تسار عت وازدادت تنوعاً وحر اكاً في العصور الحديثة والمعاصرة، فالتعارضـات الأسلوبية في الفن قد شملت التغير في الاطر الفكرية والمعرفية والجمالية والتقنية، رافقها تقويض مجمل المرجعيات السائدة، في رغبة للانفلات من أي محددات فكرية أو قيمية، ولممارسة أكبر قدر من الحريـة في التعبير، و لا شك ان ولن ان هذا قد أفضى الى إثكالية في وضـع معايير نقدية يمكن أن تحكمها مرجعيات منهجية يمكن أن تقدم توصيف محدد

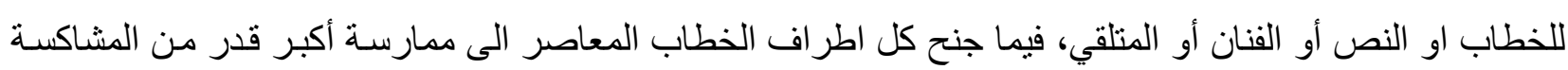

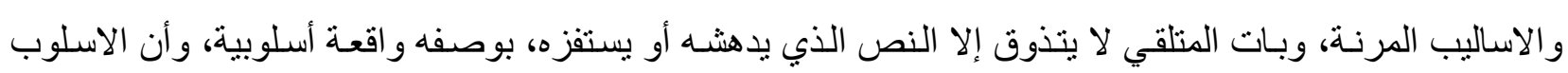

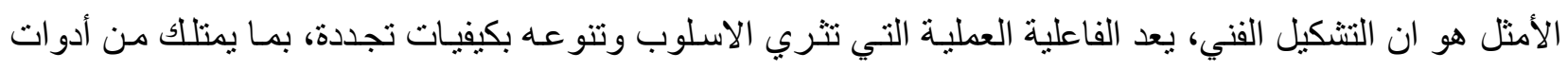

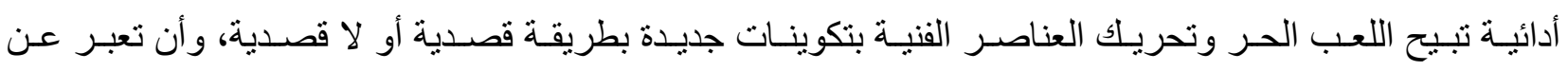
المضمون بمستوى أو آخر.

\section{الأسلوب الإزاحي، لذا توصف الأسلوبية بأنها علم الانزياحات العام.}

لقد برزت الاسلوبية من بين الدر اسـات النقديـة، التي تستو عب التحوولات الاسلوبية، بمـا تمتلك من شمولية

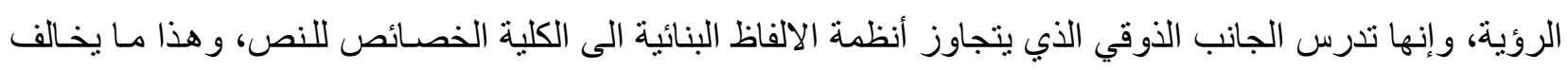

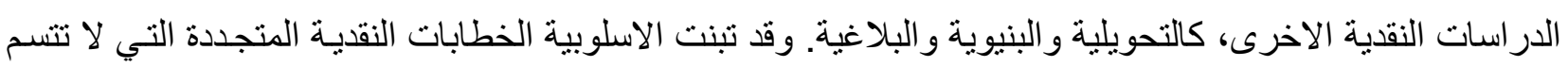

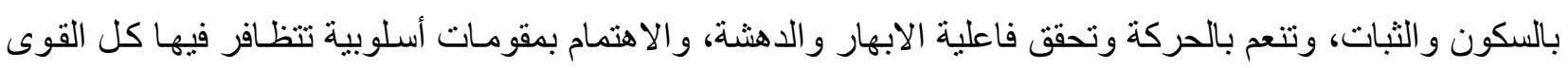

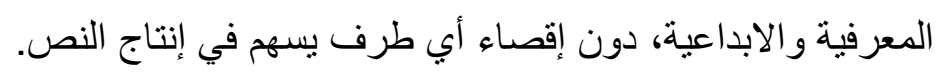
مما تقدم تتجلى مشكلة البحث عبر التساؤل الآتي: هل يمكن ترحيل طروحات الاسلوبية الى الفن ومـا ينطوي عليه من إثكاليات أسلوبية تزخر بالتنوع؟

ثانياً: أهمية البحث والحاجة إليه:

تتجلى اهمية البحث من خـلال خوضـه في الدراسـات النقدية اللسـانية ومـا تتميز الاسلوبية خاصـة، ثم كيفية إيجاد عوامل مشتركة بين الاسلوبية كتنظيرات مفاهيمية لسـانية، وبين الاسـاليب الفنية والتشكيل الفني ببعده العملي، 
و امكانية الترحيل بين مجالات قد تبدو متعارضة، وللبحث أهمية اذ يطلعنا على الكيفيات الاسلوبية في الفن وتنوعها وتحو لاتها عبر الزمن ومحاولة تأطير ها مفاهيمياً بما يتلائم وطروحات الاسلوبية. وبذللك ينطوي البحث على أهميـة

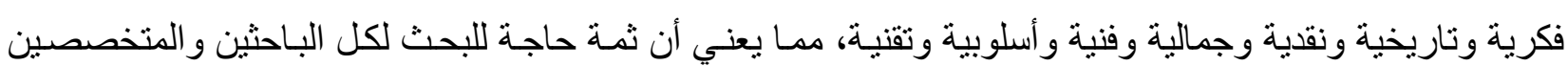
في المجالات المذكورة. ثالثاً: هدف البحث: يهذف البحث الى تعرف اشكالية الاسلوب والاسلوبية في التشكيل الفني. رابعاً: حدود البحث: يتحدد البحث بدراسـة إثنكالية الاسلوب والاسلوبية في التشكيل الفني كنظريـة نقديـة، ومحاولة إيجاد مشتركات بينهما، عبر الاساليب الفنية المتتوعة عبر فترات زمنية طويلة من ناريخ الفن. خامساً: تحديد أهم المصطلحات الاسلوب (Style): جاء في (لسان العرب)، أن الاسلوب هو الطريق والوجـه والمذهب، يقال أنتم في أسلوب سوء ويجمع أساليب و الاسلوب الطريق تأخذ فيه، و الاسلوب الفن، يقال أخذ فلان في أساليب القول، أي في أفانين منهـ [ [1].

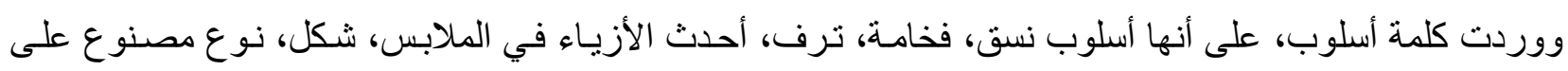
ثلاثة أثكال [ץ]]. ويعرف الأسلوب أصطلاحاً، بأنه جزء متكامل منسف تاريخياً ومستقر من نسف خيالي ووسـائل ومناهج التعبير الفني، التي تؤكدها مماتلة المضمون الجمالي والاجتماعي. كما يعكس الاسلوب الظروف الاقتصـادية

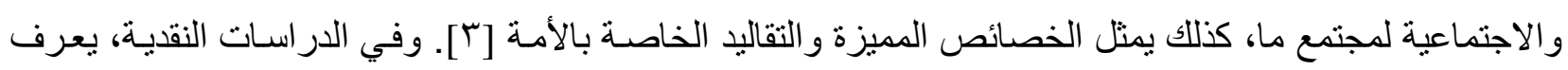

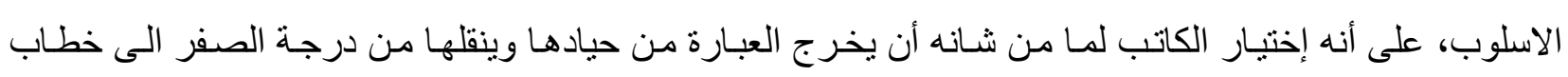

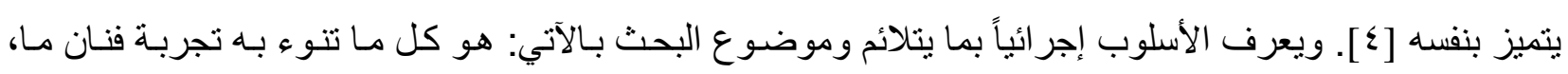

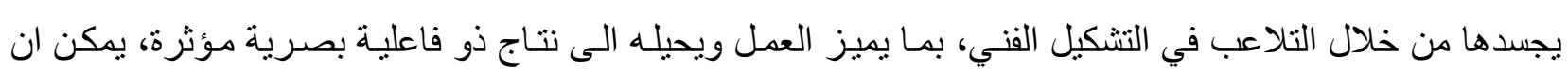
تتلائم وطروحات الاسلوبية. الأسلوبية (Stylisties) أثتقت الأسلوبية في الأصل من كلمة اسلوب سبق ذكر أصله اللغوي.

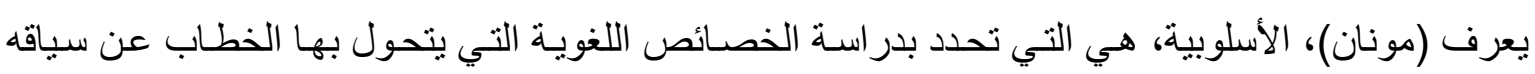

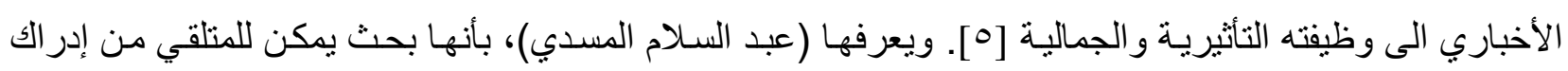

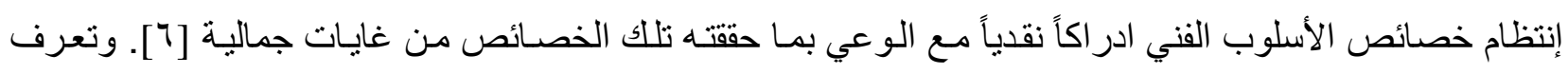
الأسلوبية إجر ائياً بما يتلائم وموضوع البحث بـالآتي: هي علم الاسـاليب، التي تدرس النواتج اللسـانية وخصوصيتها

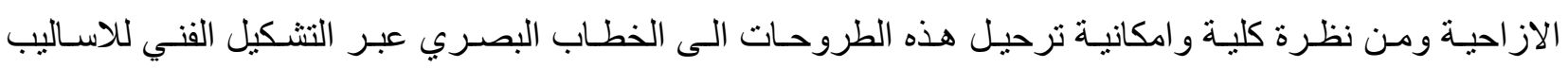

\section{النصل الثانيــ الاسلوبية والاسلوب في الدراسات النقدية}

أبتعدت الدراسات النقدية، المعاصرة خاصة، عن الأفكار السكونية والثنابتة، و النزوع الى ممارسـة المزيد من الحركة و الحرية وتفعيل عوامل الدهثة والمفاجأة، لا سيما ما يتعلق بالابتداع الأدبي و الفني حتى أصبح من الثنائع في الخطابات النقدية والدراسات الاسلوبية، أن السمات الأصلية للنص، امتلاكه عنصر المفاجأة والمعارضة للنمط وتغيير أفق التوقع لاى المتلقي وتكثيف حافز الاكتشاف. 
ان الظـاهرة الثـعرية تعد عمـلاً إبداعياً يمكن ان يكون متماسكاً أو غير منماسكــ كمـا تنظر اليه الاسلوبية الحديثة- فتجد ان النص يمكن ان يفرز إثكالية العلاقة بين البنى السطحية والعميقة، وان الاختلاف في النصوص يعود الى الصلة بين المألوف و اللغير المألوف، وبكلا الحالتين يمكن الكثف عن المتغير الدلالي، سواء استقر فوق سطح العبار ات، أو وضعت لتتخفى بين العلاقات، وهذا الامـر يتباين من نص لآخر بـأختلاف حركيـة العلامـات الدلالية.

أن ثمة تجانس بين الاسلوبية والثـعرية، وأن الاسلوبية في الحقيقة هي الثـعرية، وتعد الاسلوبية من فروع

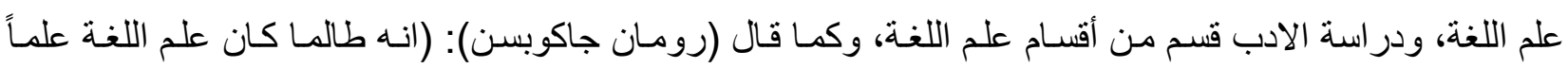

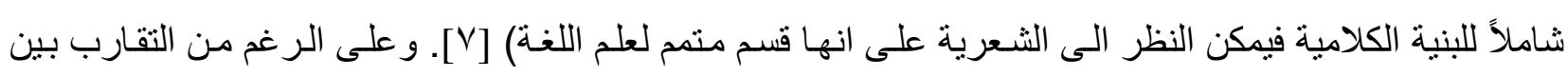

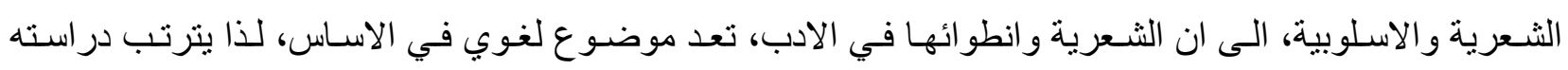

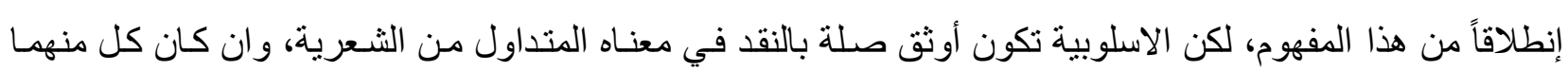
يحمل سمة الخطاب الادبي. وقد حرص (عبد السـلام المسدي) في كتابـ (الاسلوبية والاسلوب) الى منح الاسلوبية

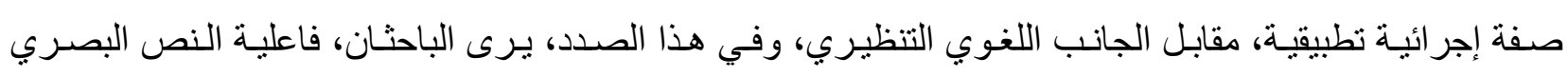
التشكيلي في تعميق المنحى التطبيقي للاسلوب.

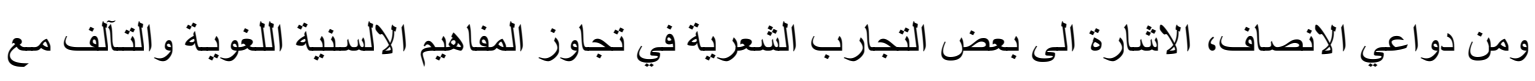

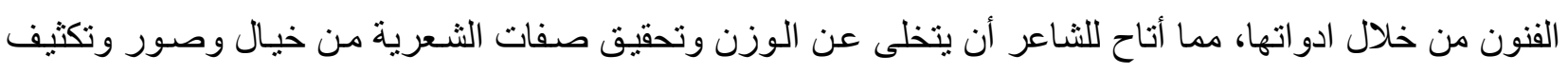

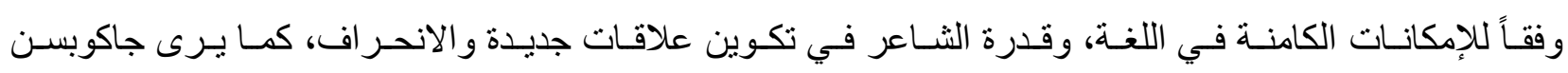

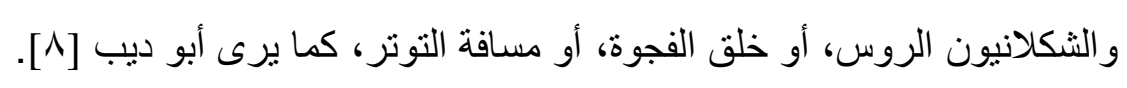

أن الاسلوب، استخلاصاً لما تقدم، مصطلح مرن يصعب تقديم توصيف له و لآلياته، لاسيما وأن الاسلوب لا

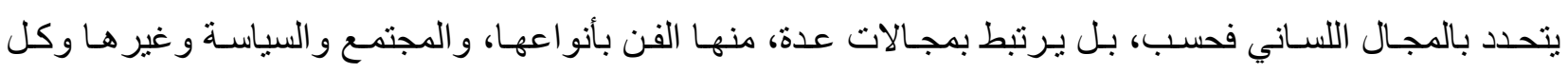

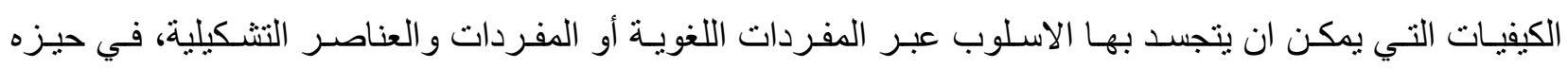
المحدود أو كأساليب في المر احل التاريخية والعصور، كحيز أكبر، أو تحول الاسلوب من حالة إلى نقيضها. أن القاعدة الاسـلوبية تعد النص الادبـي نفسـه هو المعيـار الذي يقاس اليـه الانحر اف، ويقوم على العلاقـة

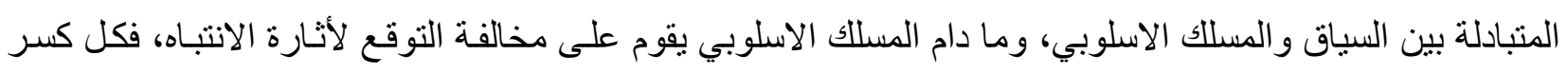
متعدد للسياق هو مسلك أسلوبي [9]. كما أن النص يحمل في ثناياه لغتين ومعنى النص فيكون محصلة للتأرجح بين

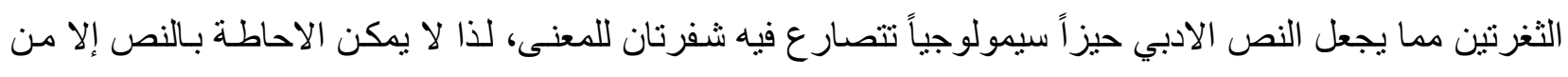
خلال الاحاطة بلغتيه معاً حين تكون متفاعلة [ · ] وفي الخطاب البصـري، يتر افق وينمو الأسلوب والثكل سوية، وتـاريخ الاشكال ـكمـا يرى ولفن- يمكن

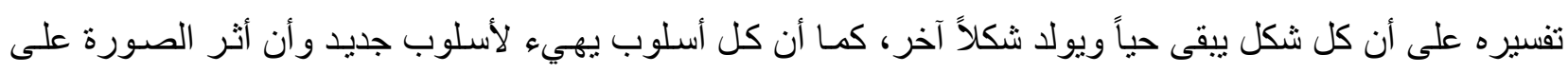

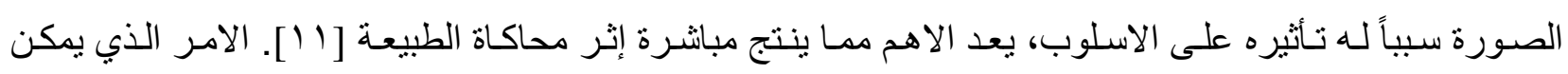
الاسلوب من إطلاق شيفر اته ومكنونه الدلالي، وهذا يعطي للاسلوب حيوية التحول و التحرر من الانماط السكونية. 
ان التحو لات في الاساليب لا تقتضي ان تكون المعاني وحدها هي المجسمة لجو هر الاسلوب، فمـا الاسلوب

سوى ما يضفي على تصور اتنا من نسق وحركة، ومن البعض من عدّ الاسلوب صورة خاصة بمنتجه، توضح طريقة تفكيره ونظرته وتفسيره للاشياء، بمـا يعني أن الاسلوب هو فلسفة الذات في الوجود، ويغدو الاسلوب هو التمـازج الذي تختط فيه تلقائية الاسلوب والذات المنتجة له، أي أن الاسلوب هو الانسان ذاته، لذلك يتعذر انتز اعهه أو تحويله

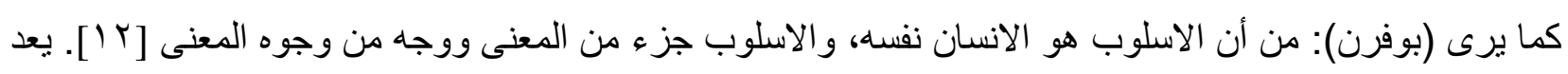

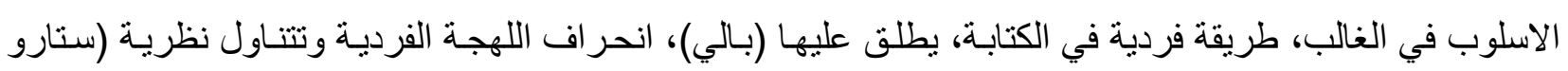
بنسكي)، تحديد ماهية الاسلوب بوصفه إعتدالاً وتوازناً بين ذات التجربة ومقتضيات التواصل، فيغدو الاسلوب بمثابـة

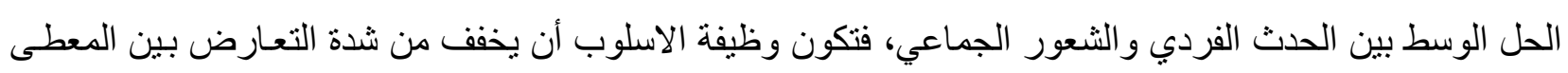

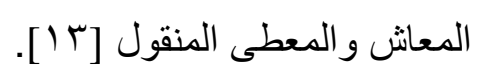

ولو إفترضنا وجود ثابت في لغة الثعر، يبقى موجوداً رغم الاختلافات الفردية، بمعنى وجود طريقة واحدة

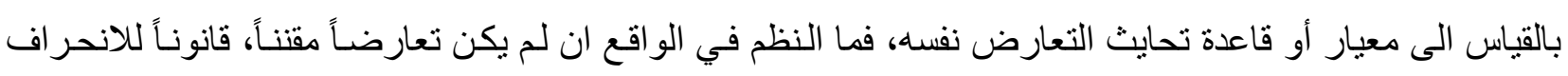

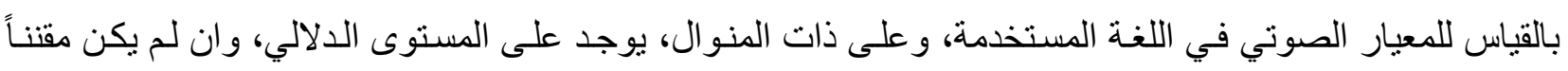

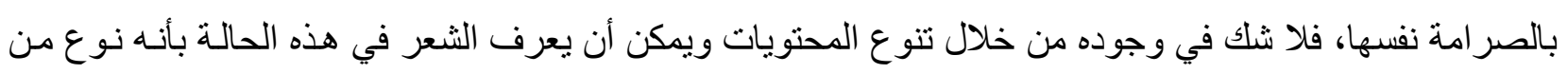

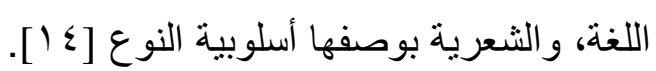

يشكك ريفاتير ، في القدرة على الكثف عن الصفات الاسلوبية المزاحة عن المعيار اللساني في النص اذ يجد

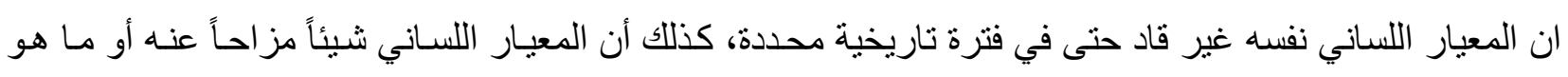

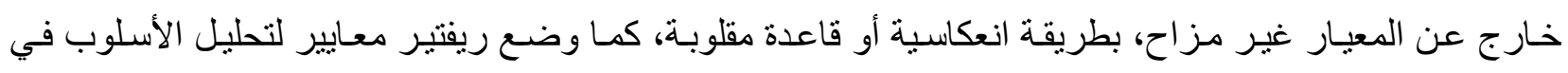

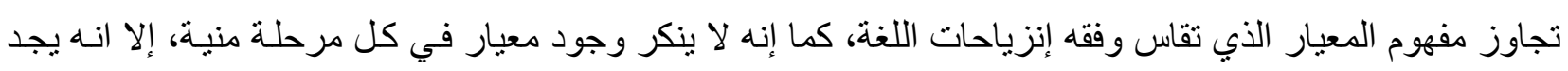

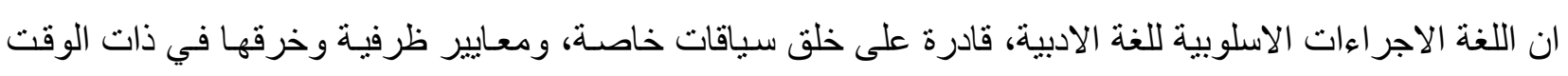

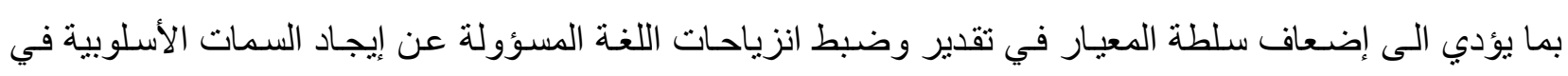
النص الادبي [10] [10]

مما تقدم يمكن أن نلمح إمكانيـة ترحيل التنظير اللسـاني على الاسـاليب في الخطـاب البصـري التشكيلي بمـا

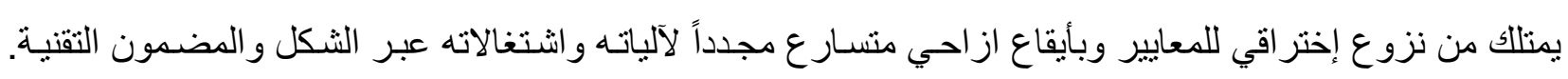
و هذا ما يتو افق مع تطلعات (جاكوبسن)، بوصفه للاسلوبية، بأنها بحث عما يتميز بـه الكلام الفني عن بقية مستويات الخطاب. وكذلك عن سائر أنواع الفنون الأنسانية.

أو كما يرى (بالي)، ان معدن الاسلوبية، هو بما تقوم به اللغة من وسـائل تعبيريـة تظهر المفارقات العاطفيـة

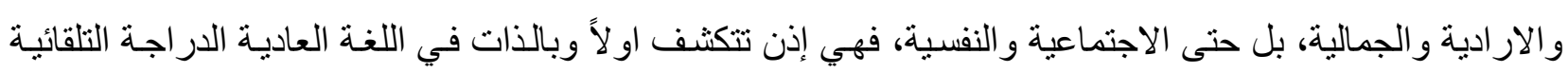

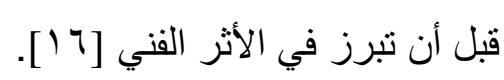

من زاوية مقاربة، فأن جماليات الصور التداولية تختلف في عد الفراغ الذي يمكن للمتلقي ملئه يظهر جراء التناقض بين الكفاءة التو اصلية العادية وكفاءة الانزياح، وبذلك يمتلك الدليل اللساني الصوري في النص الادبي، تعدداً 
ثلاثياً، الخطي والمرجعي والتواصلي، وفقاً لنقطة شروعنا من هذا النوع أو غيره، فالتعدد هذا يظهر في شكل قراءات

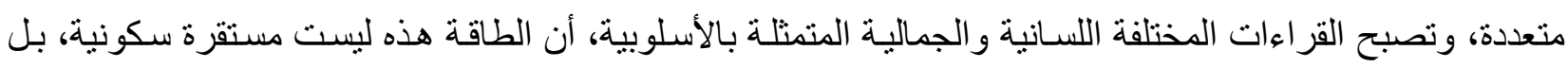

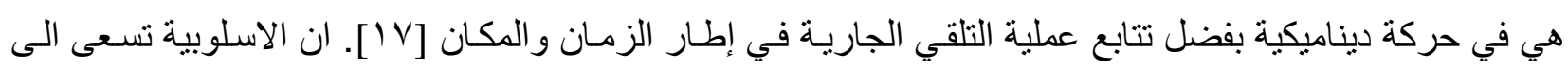

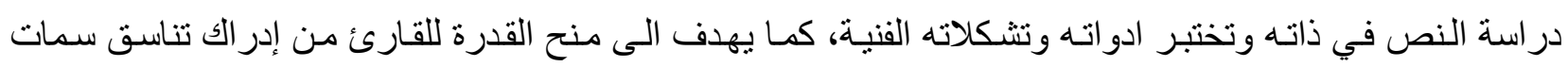

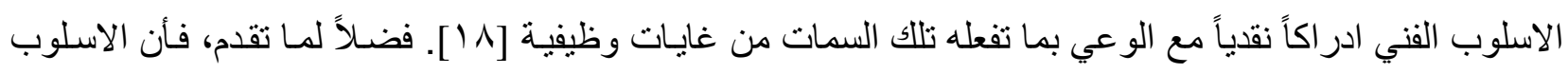
يصف القوة الضاغطة التي تتسلط على حساسية القارئ عن طريق إظهار بعض عناصر الكلام ودعوة القارئ على لـى لإنى

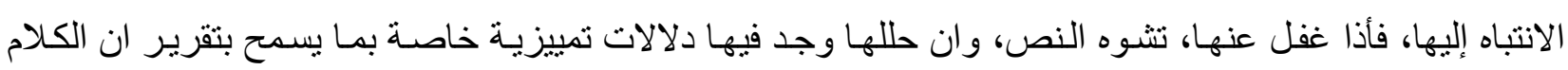
يعبر ، والاسلوب يميز [19]

ان الصلة بين الاسلوب و التقليد، وثيقة، لا بتبني التقليد بل بمعارضته و الانحر اف عنه، فيرى (نحوته) أن

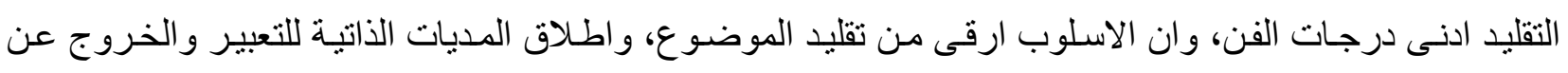

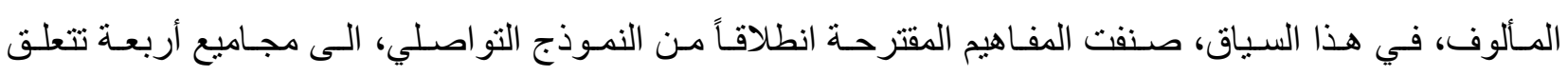

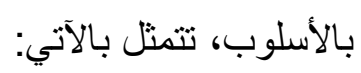
1 - يعبر الاسلوب عن شخصية المؤلف/ المرسل و عقليته وتوجهه الفكري، وهو مفهوم تعبيري تكويني للأسلوب. r- للأسلوب أثره في المتلقي/ القارئ، ناتج عن خصائص النص الداخلية، مفهوم التأثر العاطفي.

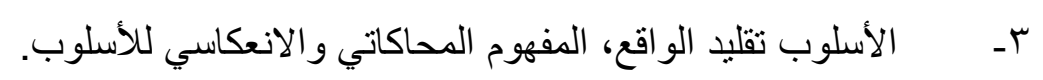

ع - وصف الاسلوب بكونه تأليفاً خاص باللغة، يمثل المفهوم التأليفي المرتبط بالنص ذاته، اذ يكون توجـه الباحث فيه موضوعياً في در اسة الاسلوب في تفريق طرفي الاتصال المنتج و المتلقي ويهتم بالنص ذاتـه [•r؟]، هذا التصور

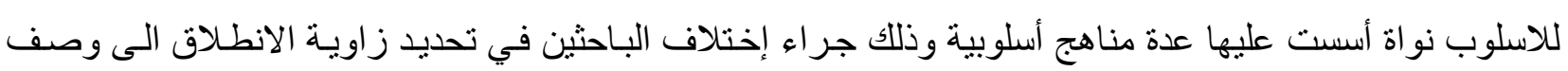

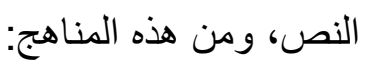
أـ أسلوبية الانزياح: وهي تقابل بين اللغة الادبيـة الرفيعة وبين اللغة الاصطلاحية، بمـا ينتج لغة من صور

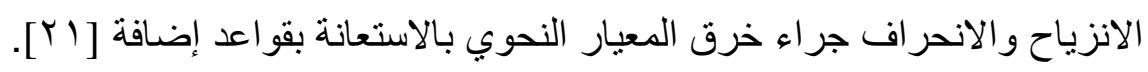
بـ الأسلوبية الاحصـائية: وهي عملية تحديد ملمح أسلوبي للنص عن طريق الكم و ابعـاد الحدس لصـالح القيم العددية، وهذا المنهج يدخل في علاقات جدلية مع بقية المناهج الاسلوبية [rre]. ج- الاسلوبية السياقية: وتقوم على المفارقة المتولدة عن الانزياح داخل النص، ناتجـة عن ادر الك عنصر نصي متوقع منبوع بعنصر نصي غير منوقع.

فالأسلوب ليس مكوناً من عناصر المفارقة فحسب، بل من السياق المتوقع (الاسلوب= السياق + المفارقة) [بr]. نخلص مما تقدم، الى تو افق مجمل المنظرين في الدراسـات النقديـة، على الاشكالية الاصطلاحية للاسلوبية و الاسلوب جر اء حركيـة ومرونـة المصطلحين، وجفاء الثبات و المعياريـة السكونية، لا سيما في الكيفيات الاز احيـة للأسلوب، وان هذا الحراك والتنوع هو ما يغذي عملية الابداع. 
وفي العموم، فالأسـلوبية هـي النظريـة التـي تدرس اللغـة مـن الناحيـة الاسـلوبية، فتدرس اسـاليب النصـوص

اللغوية وطريقة تكوينها ضمن نسقها العام، وفقاً لنظرة كلية.

أمسا الاسلوب فهو الطريقـة التي يسلكها الاديب في تأليف نصـه معتمداً على حدس القارئ وذوقه وثقافتـه فالأسلوبية تدرس الجانب الذوقي الذي يتجاوز أنظمة الالفاظ وبنائها، الى الخصائص الكلية للنص، كذلك ومن شمولية النظرة، فالاسلوبية تهتم بالكاتب ابداعه وذوقهه وروحـه و انفعالاته النفسية وطرق تعامله مـع النص شكلاً ومضموناً،

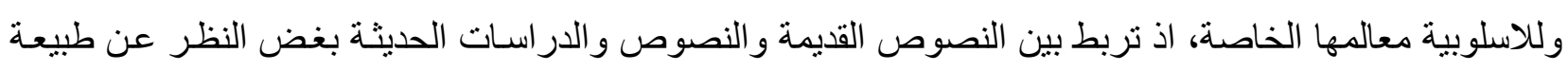
العصر وتفاصيله، فما يهمها هو الناتج العام لذلك الترابط وبمـا يجعل للنص الجديد روحه الخاصـة وفي تمييز بين

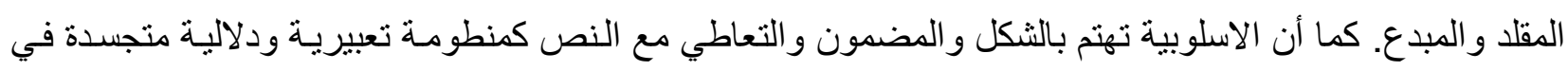
بنية شكلية فاعلة.

وللاسلوبية طرقها في النظرة الى النص، منها الاهتمـام بادلر اسـة ابتداءً من الاجزاء ثم التدرج صسوداً الىى

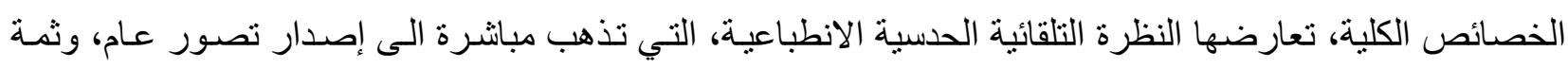

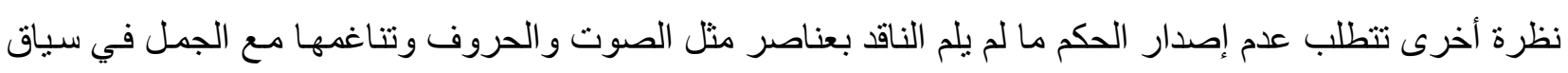
النظرة الكلية.

وفقاً لما تقدم، نسعى الى ترحيل التنظيرات النقديـة اللسـانية الى منطقة التشكيل الفني وايجـاد مبررات عملية تطبيقية تضطلع بها النتاجات الفنية عبر العناصر الفنية ووسـائل التنظيم الجمالي كآليات في التشكيل، ومضـامين لها لها منظوماتها الدلالية والجمالية، وهذا ما سيثر ع به الباحثان في الفصل اللاحق، عن قرب.

الفصل الثالثـ إشكالية الاسلوب في التشكيل الفني (فصل تحليلي)

يرمي هذا الفصل الى تقصي أساليب التشكيل الفني و ما أسفر عنه من إثكاليات جراء الكم الكبير من التنوع الاسلوبي الذي ويصل الى حد التعارض ـ و محاولـة ايجـاد رابط منهجي مـع الدر اسـات النقدية الأسلوبية ، التي تم تناولها في الفصل السابق إذا كانت الأسلوبية علمـا يعنى بدر اسـة الأسلوب بوصفهـا فر عـا من فروع اللسانيات.. فأن للأسلوب أبجديات اثراءاته في المجالات الفنية والأدبية والجمالية او من خلال تنافذاته في الفروع الإنسانية والعلمية

الأخرى عبر نر اكمات من التحليلات الفنية تاريخياً.

وقد تتقسم الأساليب تبعا لتأثير اتها في المتلقي او تبعا لمنحاها التعبيري عن شخصية الفنان وأحيانا ينت تبويب للأساليب طبقا للمنحى الوظيفي لهذه الأساليب فهنالك أسـاليب تنحسر آلياتها بحدود المعالجات الأدبية والفنية وأخرى

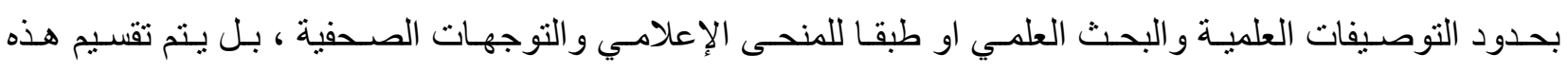

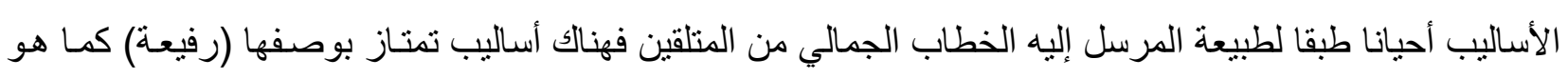
الحال في مرحلة من المر احل التاريخية لطبقات اجتماعية ارستقر اطية مثنا في المجتمع الباريسي او المجتمع الروسي

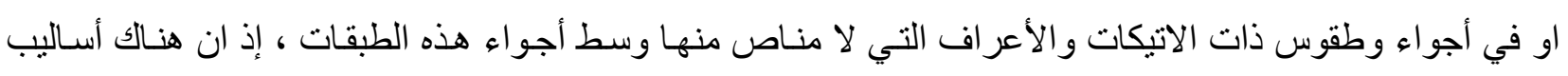
ترتبط بالثعبية و البساطة ..فنتاجـات (الفن الثعبي) او مـا يطلق بـ (فن البوب ارت - pop art) على سبيل المثال 
يخرق مسميات الثقافة الرفيعة ليصعد من مديات الثقافة الثعبية ، بل احيانا يتم تصنيف الاساليب تبعاً لددى المحاكاتيـة

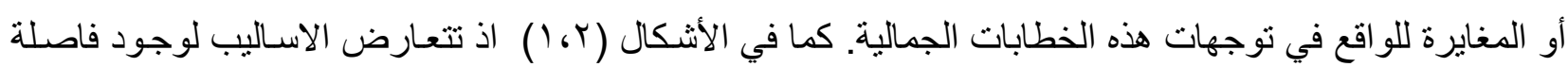

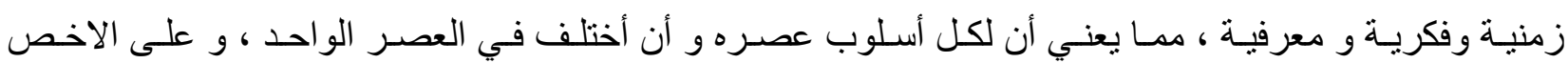

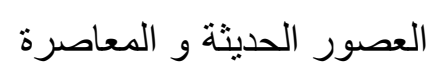

إن الأسـلوب إنمـا يقترن بماهيـة الثخصية المبدعـة بانفعالاتها وتـداعياتها الاسقاطية سيكولوجيا و الكيفيـات الخاصة بمعالجاتها الفنية اذ يعرف الأسلوب بوصفه شخصية الفنان ذاته بل هي ـ انا ـ الفـان متجسدة في ثنايا عمله

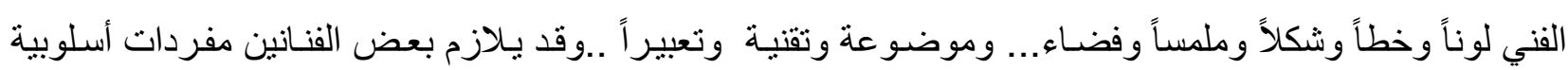

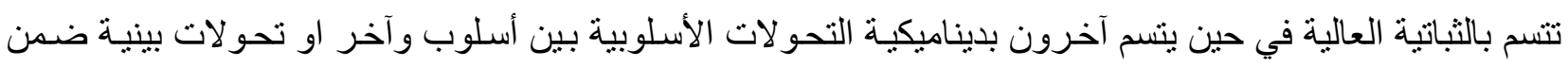
مسـار ات الأسلوب الواحد ويقترن ذلك في حقيقة الأمـر بجملـة من المرجعيـات والمؤشرات المعقدة الوجدانيـة منهـا و الثقافية والبيئية و الوظيفية و على مستوى النضـج والتحول الفني ـ وإذا كانت الأسـاليب التي يتسم بها الناس عموماً

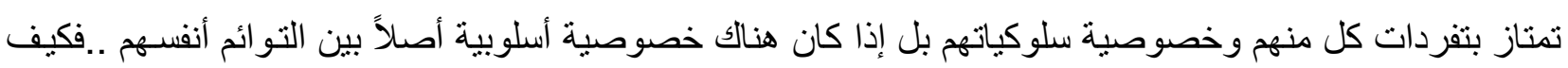
الأمر في عالم الكتابة والفن ، إذ على الرغم من التوجهات المدرسية والأكاديمية او خطابـات وبيانات ذات الحركة او

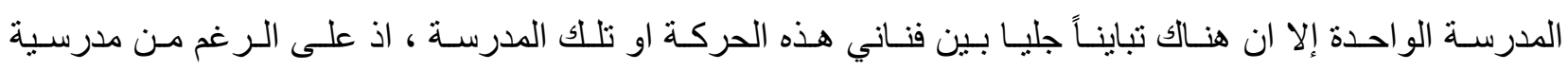
الكلاسيكية الجديدة فهناك تفـاوت أسلوبي بين رسومات (دافيد) و(انكر) و (كرو) ، ومـع ان عصدر النهضـة تلتسم

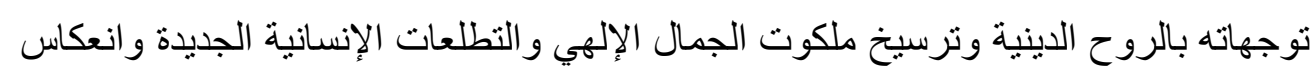

اثر اءات النهضة الفكرية والاقتصادية في المجال الفني فـان لـ (مايكل انجلو) الثكل (ب) أسلوبه الذي يتسم بالنحتية السوبرماتية ذات الهالات التي تمزج بين ما هو مقدس وما هو أنساني ..اذ ينتج مشـاهد مشرقة قياسـا بمشـاهد القرون الوسطى وأسلوبه هذا يتباين مع أسلوب (دافنشي) الثكل(ع ) ذللك الأسلوب الذي يتدفق بالثـاعرية والغنائيـة

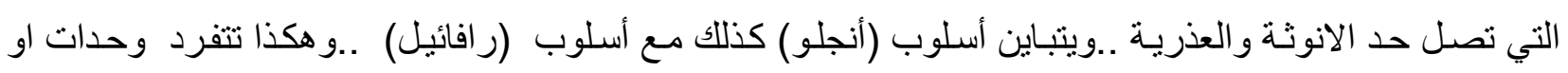

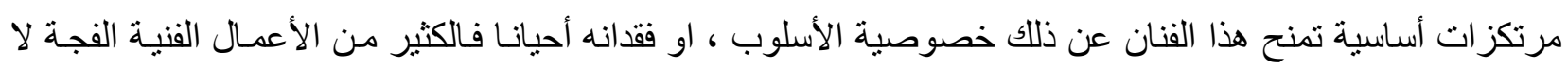

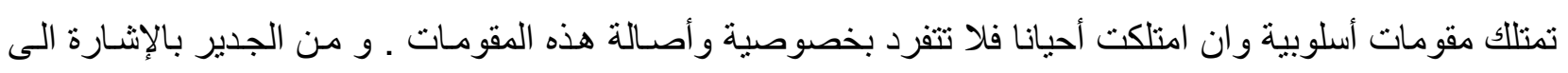
التميز بالأساليب ،إذ أستخدم (ولفن) لخمسة ازواج بين المفاهيم المتناقضة في المقارنـة الأسلوبية بين الفن الكلاسيكي في القرن السادس عشر و بين فن البـاروك في القرن السـابع عشر وفقاً للتحول في العوامل الفكريـة و التاريخيـة و الجمالية ، و هي

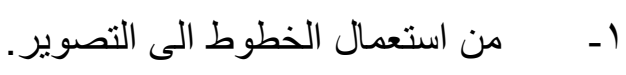

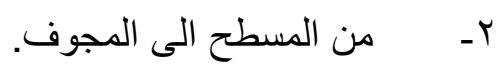
r- من الثكل المغلق الى الثكل المفتوح. ع - من التعدد للوحدة .

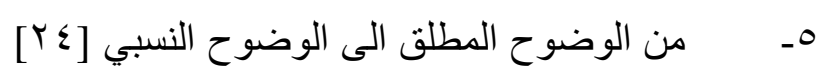


لاشك ان للعناصر الفنية ووسائل الربط وطبيعة المنظومة العلاقاتية بين هذه العناصر تجذر اتها ودلالاتها من خلال جملة من التأثيرات و المرجعيات المباشرة منها وغير المباشرة والتي تتنتغل على مدركات ومنظومات حسية

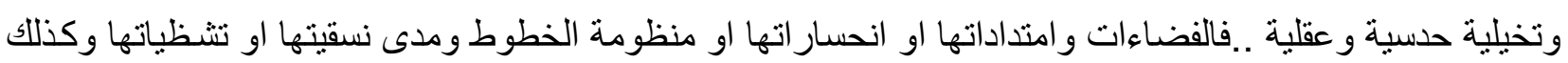
على مستوى اللون ومدى عفويته او فور اته الانفعالية او دلالاته الرمزية وقد يغدو الثكل أرضية والأرضية شكلا في

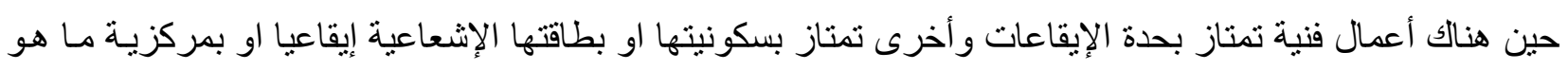

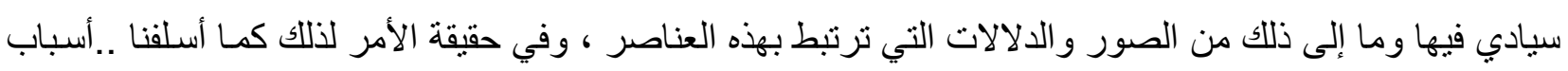

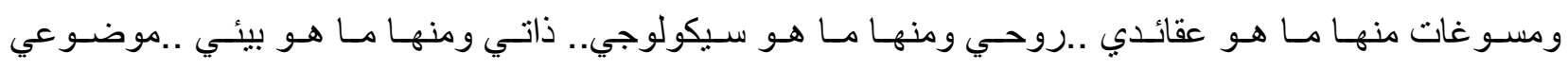
محيطي..فضلا عن اختلاف طرق التفكير و الرؤيـة والنضـج ..فمخرجات النتاجـات الفنية على سبيل المثنال في بيئة الريف تمتاز بعفوية و عضوية وانسيابية خطوطها وانفتاح فضاءاتها وتعبير اتها التلقائية المباشرة ،اذ تصطبغ العناصر وطبيعة العلاقة فيها بمسميات البيئة ذاتها لتتفرد بتكر ار سمات او وحدات معينة تمنحها بعدا أسلوبيا. ويبقى للمنحى الرؤيوي أو القصدية الرؤيويـة للفنـان أثرهـا الفعـال الذي يوازي الانتقائية الأسلوبية إذ تشتغل

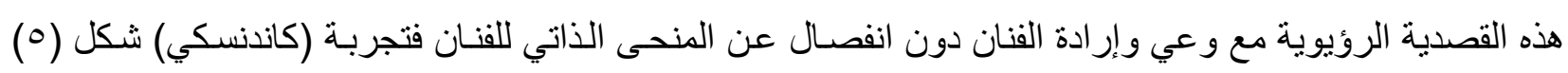

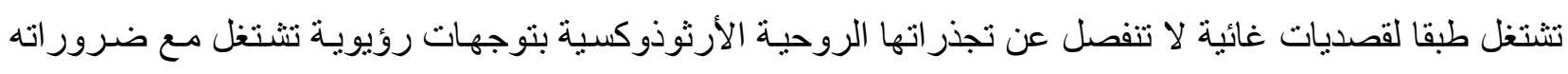

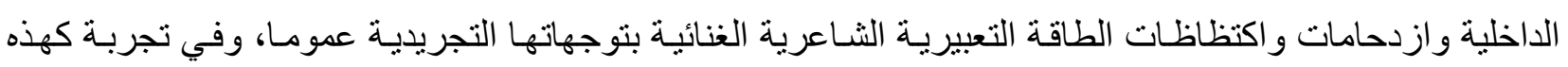

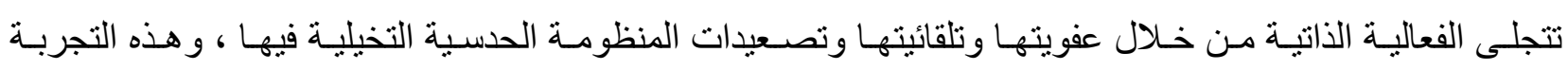
بتفرداتها الأسلوبية هي غير ها مع تجربة (موندريان) شكل (T) وحديته و واستفزاز اته الجمالية للمتلقي رؤيـة أسلوبية

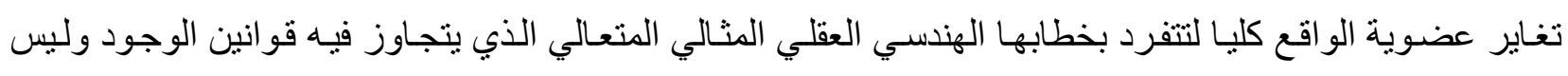
الوجود ذاته ..قو انين الوجود .. متوسماً القو انين الرياضية التجريدية المحضـة لذلك الأصل المثالي الأفلاطوني الذي لئي

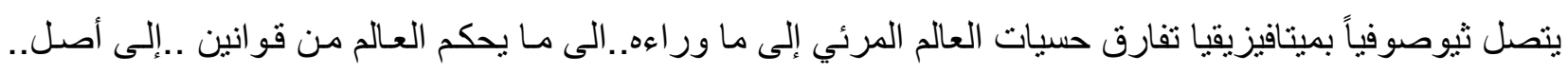
تجد فيه كل الأشياء انطباقاتها الكلية معه.

و إذا كانت حفريات الأسلوب تتصل مع تحو لات تاريخية ترتبط بموقف الإنسـان مع المنظومـة المحيطية كمـا هو الحال في السلوكيات البدائية الصرفة التي تتصل مع ما هو آني دون تفكير مستقبلي ومع منظومـة فكريـة حسبية وحسية تتماهى مع قوى وحاجـات شمية وذوقية وجنسية وبايلوجية ..إلى مرحلة تكوين القرى الزر اعية ومر احل فئل

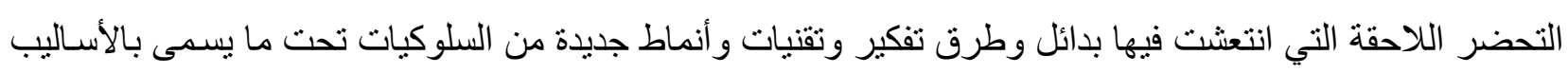
الجديدة والتي تمثنل أنماطـاً تنظيميـة متجددة تمثنل علاقـة الإنسـان مـع حيثيـات العـالم الخـارجي وتشـذيباته الأسلوبية لمفردات هذه الحيثيات عبر التبويب و الإدارة والتنظيم والتخطيط و إعادة التخطيط و عمليات التحليل و التركيب و التقويم وبما يمنح تلك الأساليب سمة العصر والتجديد ..و لاشك ان هنـاك تحو لات تشكل هوة او إزاحسات هائلة تتفجر فيها أساليب جديدة كما هو الحال في إفرازات أساليب تشتغل مع منظومة جديدة لها رؤيتها التفكيكية الخاصة لفنون مـا بعد هلئ الحداثة .. إذ أنها منظومـة تشتغل مـع الاستهلاكي و العـابر و الفضـائحي و التفكيكي و التحريضـي و الاستفز ازي الخنتي

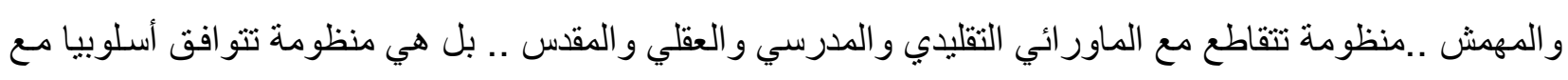
مخرجات عالم اليوم الذي أمسى فيه العالم محض قرية في ظل الثورة المعلوماتية المطردة في مجتمع ما بعد الصناعة ولي ولئ 
والاشتغال في مخاضات المناهج النقدية ما بعد البنيوية ..منظومة تغادر المنن إلى الهامش وتتشظى إلى مالا نهاية من

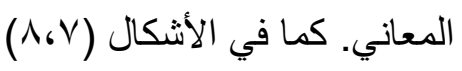

وقد يرتبط الأسلوب بسمة تصطبغ بها توجهات العصر بأكمله كمـا هو الحـال في الأسـاليب الرومانسية التي

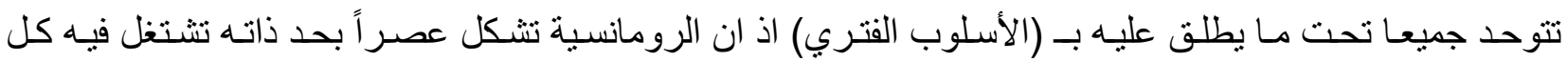

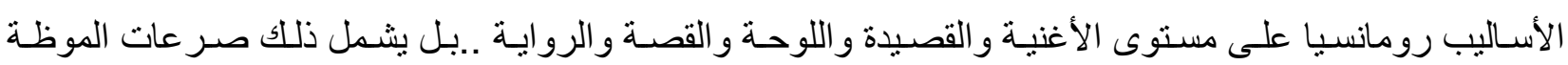

والتقاليد السيسيو - رومانسية. الشكل (9)

ولا تقتصر الأسلوبية كما تم التتويه الى ذلك على المنحى التطوري المتحضر على مسنتوى الإنتاج الفني ، بل هي سمات تفرز نفسها من خلال ملازمتها خصوصية الأداء في نتاجـات فنيـة مـا .. فأسلوبية النتاج الفني البدائي ..أسلوبية تتسم بالواقعيـة غير المباشـرة ذات الدلالات الرمزيـة الى حد مـا وهي نتاجـات تمتـاز بالسماجة و التلقائيـة و الخشـونة تتو افق مـع خشـونة وسماجة وقدريـة الوسط الخـارجي وطبيعـة سلوكيات الفورات الانفعاليـة للبدائي ذاتـه

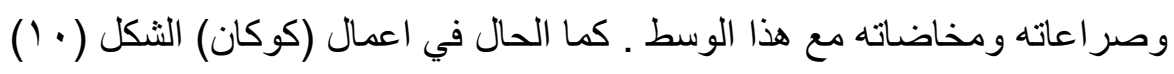
كما يتصل الأسلوب بطبيعة مرجعيات محددة تمنحه خصوصيته وتفرده..فالأسلوب في الفن الإسـلامي يستقي

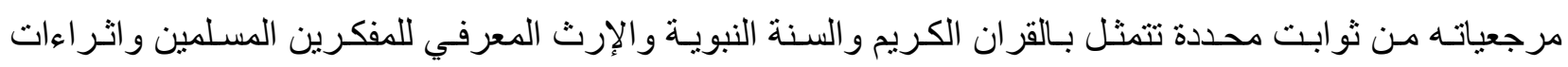

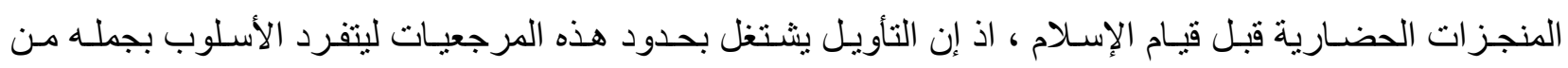
السمات في فن التصوير مثنلا كالتسطيح و التكر ار والتجريد والوحدة في التنوع او نسـاوي المنظومـة القيميـة لوحدات العمل الفني كما في الثكل( (1) .. و هكذا كان الفن المصري القديم يحتفظ بخصوصيته الأسلوبية اذ تتسم وحداتـه البصرية بالتكرار والثبات لجملة من المرجعيات الوحدانية وان لهذه الثو اهد الأسلوبية أحكامها الجمالية التي تتو افق بقان

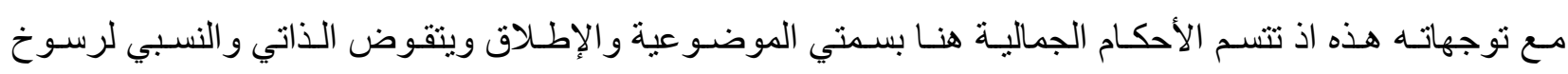
العناصر و المعالجات ذات المرجعيات الموضوعية ولتو افر مرجعيات لا مناص من الركون إليها كما في الثنكل (ب ا ) .و هنا تشكل الملامح الأسلوبية أبعادا على مستوى الفكر والتلقي والذائقية والأحكام الجمالية.

قد تشكل الأسلوبية في تفحصها للمعالجات الفنية الجديدة لأسلوب يشكل إزاحة بحد ذاته ..ازاحة لقرون من فن الرسم ..فهناك نتاجات تشكل عنبة تفصل بين عالمين ..عالم يقوض بفعل هيمنة الإزاحة الأسلوبية الجديدة و عالم جديد يستقي مصادر إبداعه من ذات العتبة الخلاقة على كل ما هو تغريبي من الاسـاليب وجديد ، ولنسمي على سبيل هليل

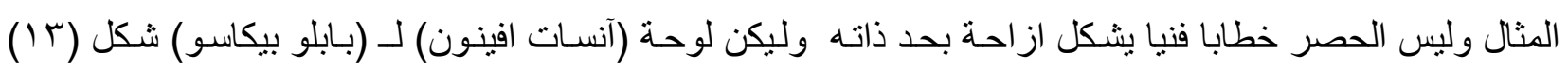

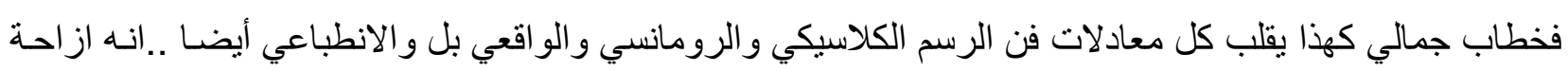
لرؤيـة جديدة للأشياء يتمثل بخلق قيم استطيقية جديدة تؤسس طروحات رؤيويـة جديدة في عالم التجريد و التعبير

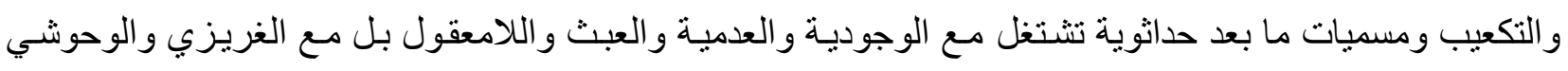

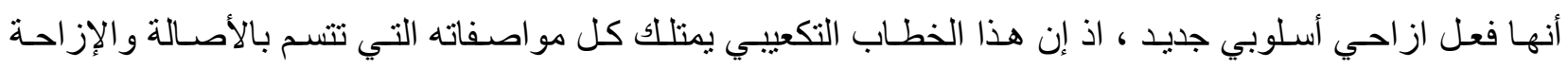
و الاختر اق ..و هو أسلوب فني لا منتمي ولا بعود الى لا منتمي اخر يتمثل بـ (بابلو بيكاسو). 
إن إضافات معينة ضمن معالجات تقنية قد تشكل ققزة هائلة في فن التصوير فإضافة المطبوعات اليابانية في

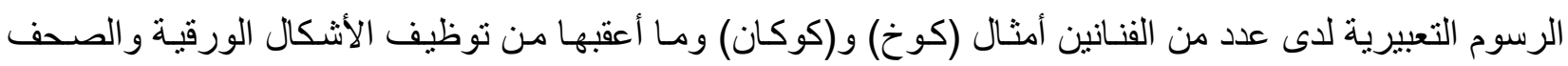

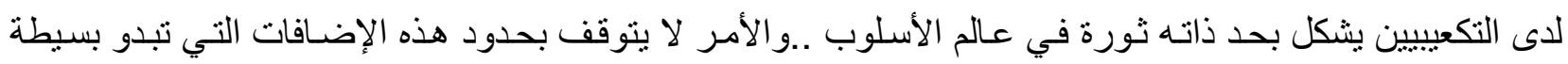

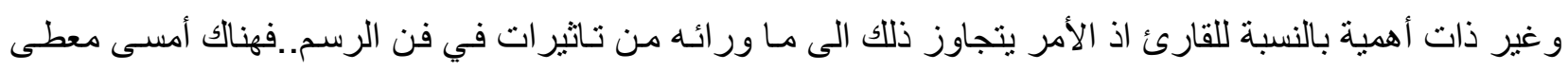

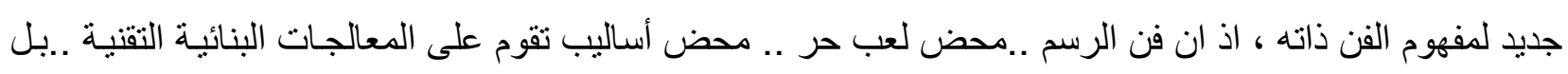

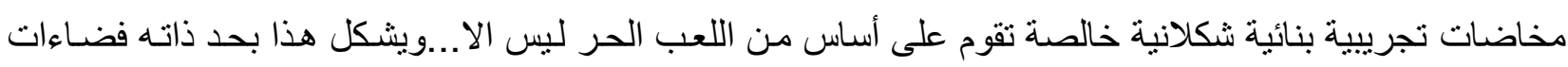

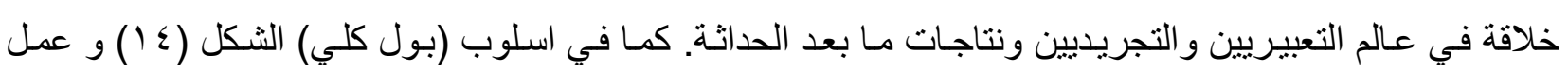
(بولوك) الشكل (10) - 20 (10)

إننا نعني بذلك حقاً عندما نؤكد مقولة ان الأسلوب يتمثل بالإنسـان ذاته ــ الفنان ذاتـهـ اذ ان نتاجات (بـابلو

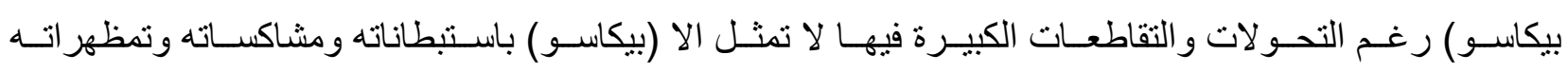

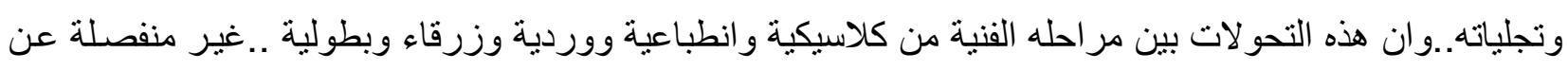
تأثنير ات جمة أخرى ولكنها لا تؤكد الا حقيقة واحدة تتمثل بترسيخ مفهوم الاسلوب الفردي.

ان الاسلوبية تعنى بدر اسـة الوحدات او السمات التي تتكرر بشكل مباشـر وغير مباشـر والتـي تمنح صفة

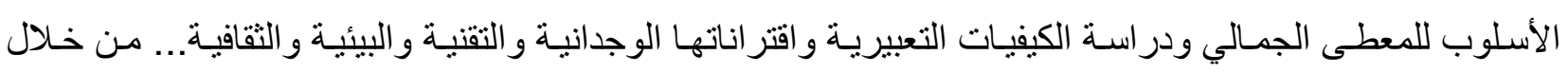

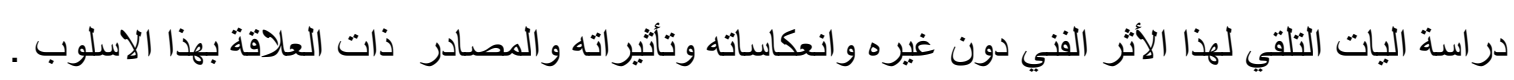
ويعد الأسلوب طريقة نعبر بها عن رؤيتنا للعـالم وللضرورات الداخلية للذات الفنية والانسـية وقد يصطبغ الاسلوب بحفريات وتوجهات ومعالجات ومسار ات إخر اجية متعددة منها ماهو رمزي او تعبيري او تجريدي ومـا الى ولى ذلك من المسميات التي تمنح الخطاب صبغة اسلوبية من خلال تظافر تفاعل الافكار و الرؤى والمشـاعر و المعالجات الأدائية والتقنية لتشكل توجهات عامة لهذا الاسلوب دون غيره من الأساليب الأخرى.

ان هناك اساليب فنية تمتاز باثر اءاتها المعقدة لنتاجات لا تمنح نفسها مرة واحدة ..نتاجات نجد فيها جديد كل

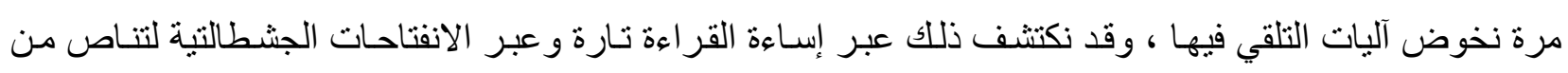
المعاني التي تتشظى ابـا ..وكسر افق توقع المتلقي ..ولناخذ اسلوبية (فاسيلي كاندنسكي) الذي لايجرد خطاباتهـ

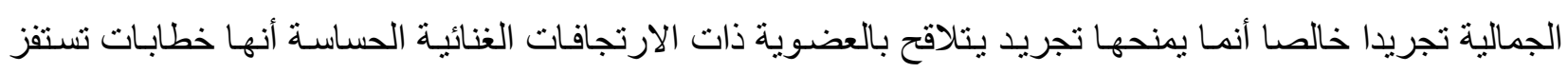

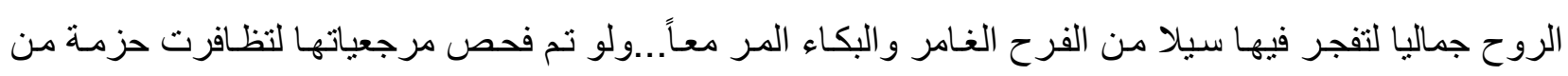
التأثير ات التي تتماهى بما لا يجعلها تعد تأثيرات محددة بـالمرة ..فتارة تطفو على السطح جلية وغير جلية تأثيرات

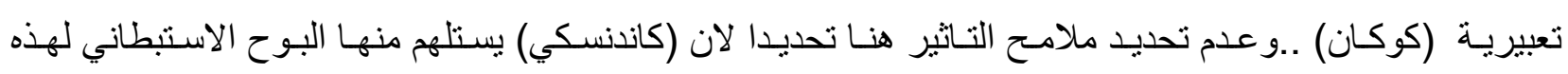

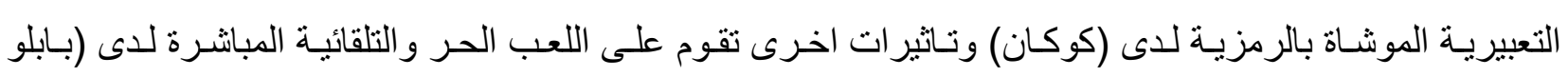

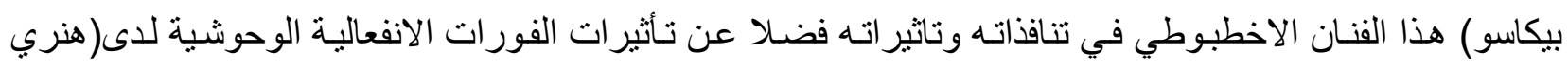
ماتيس)و عجائنه اللونية ذات التسطيحات التجريدية ..انها نتاجـات فنية عصية ان تمنح كيفياتها للمتلقي و هكذا الحسال إزاء نتاجات فنان عربي يمتلك تاسيسـاته الأسلوبية التي تتشظى إلى حد نفقد تشخيص ملامـح اي من التأثير ات في 
نتاجاته ذات المرجعيات العديدة ..منها رافدينية و إسلامية وبغدادية تأثثرات ، (مايكل انجلو) و(هنري مور) و(بابلو بيكاسو) و (ميرو) و (كلي) وتأثيرات أخرى ..ويبقى الأمر معلقا اذ لا حكم جمالي يمنح تلك المرجعيات تاثثير اتها

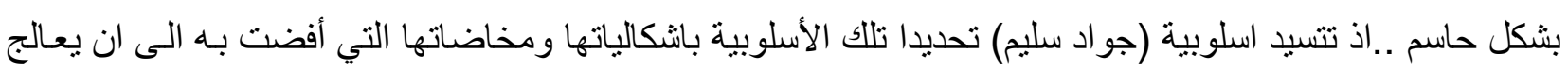

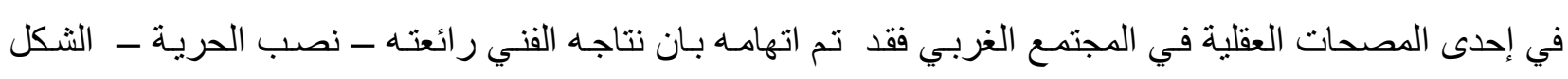
(7 ( ) مزيج من التاثيرات و التلاقحات لأساليب متعددة منها ما هو و اقعي.ورومزي..وتاريخي ولكن النقد الفني انصف

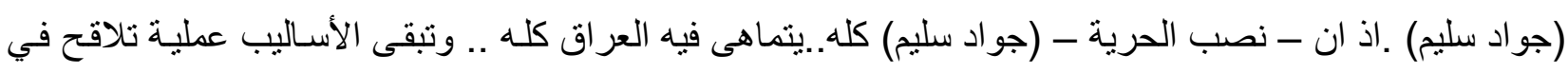

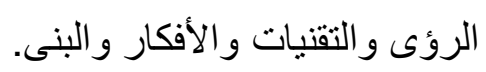

إنها إثكاليات حقيقية تضعنا عند مفترق طرق فالاسلوبية تتفحص أساليب منها ما هو فردي يخترق التعاقبات

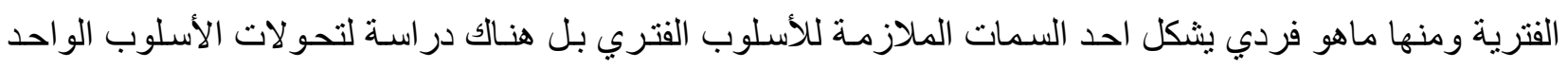
نفسه وتباين ضمن أساليب تتوحد ضمن الأسلوب الفتري ..بل هناك إثكالية في المعايير التي نحتكم من خلالها إلى في

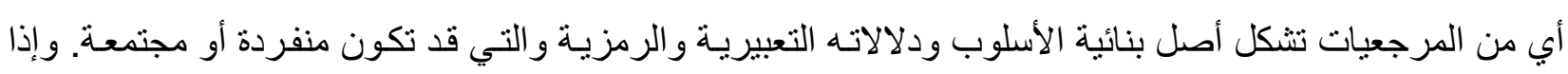
كان الأسلوب ذات الفنان نفسه فما هي مديات اقتر انه بتأثنير ات ومرجعيات أخرى تاريخية وبيئية ووظيفية ونئية ولثافية.

الفصل الرابعأولاً: نتائج البحث :

في ضوء الفصل الرابع (التحليلي) والفصل الثالث (التنظيري)، أسفر البحث عن النتائج الآتية: ا - أسفرت الاسلوبية في التشكيل الفني عن أساليب متعددة، كل منها تعاطى مع خصوصية العصر ومنظومتهـ الفكرية و المعرفية و الجمالية، فأرتبط تنوع الاسلوب بتغيير العصر، و هذا ما تجسد في مجمل الاشكال المعروضة. r- ان التعارضات و التباينات بين الاساليب في فترة ما أو عدة فترات، أسفرت عن إثكالية في قر اعة النصوص التشكيلية، تمس الاشكالية المنهجية للاسلوبية، الامر الذي بات يفرض المرونة والحر الك القيمي و الجمالي. بـ- يعد الاسلوب نسق من العلاقات المنتظمة لفنان ما، ولفترة مـا، وأن أي تحول في نسق ذلك الاسلوب، يشير

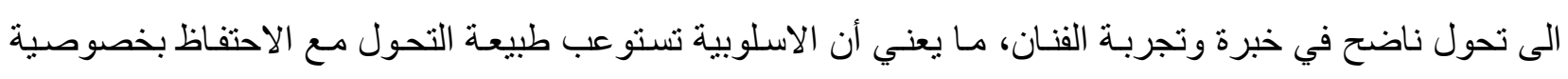
الاسلوب ووحدته ونظامه الداخلي، كما في تحولات (بيكاسو). ع - تعاطت التعبيرية من خـلال أسـاليبها ومعالجاتها البنائية، مـع المكنون الذاتي و الانفعـالات النفسية والعاطفيـة للفنان، كجزء حيوي فاعل في منهج الاسلوبية ونظر اتها الثشاملة لمكونات الخطاب التشكيلي والذي سـاد في الاسـاليب الفنية الحداثية. ــ إنطوت الأسلو بية في التتكيل الفني على أسـاليب صنفت وفقاً لتأثير هـا في المتلقي، وتبعاً للمنحنى التعبيري للفنان، وتبعاً للمنحنى الوظيفي للاعمال الفنية. 
7- تعاطت الأسلوبية في التتكيل الفني مع نصوص فنيـة لعصور سـابقة وتضمينها في النص الجديد بمعطى جديد، ومنها استخدام النتاجـات الفنية الرفيعة بتوصيفاتها الجماليـة المثالية، في اعمـال شعبية عرضية دون اعتبار لقيمتها الجمالية.

V- إتسمت الأسلوبية والاسـاليب، بالحركية الديناميكية المتغيرة ونبذ الاسـاليب الجامدة السكونية كصفة مر افقة للابداع و التي تتعاطى على نحو مجدد مع متغيرات العصر. كما في الاساليب الفنبة الحداثية وما بعد الحداثية. 1ــ تنظر الاسلوبية التشكيلية لنتاجاتها على أسـاس النظرة الكلية الثـاملة و الخصـائص العامـة، فلم تقرأ المنجز على أساس جزئية العناصر الفنية ووسائل الربط، بل لفاعلية هذه الجزئية في الكل، و هذا ما يخالف القراءة البنيوية للنص. 9- ل الفترض الأسلوبية منهجية فكرية أو معرفية محددة، فنظرتها الثمولية لا تفترض كيفيات تتكيلية، فتحمل

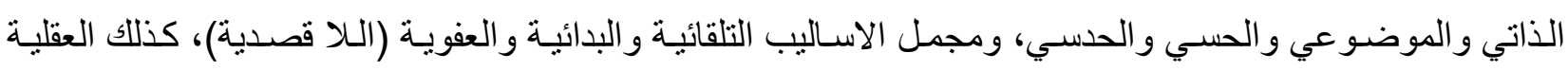
الهندسية (ألقصدية). • ا ـ تتفعل الاساليب بقوة جراء التنوع الاسلوبي، اذ ان الاسلوبية، هي عملية إزاحية أختراقية تتفاعل مـع التجديد والابتكار المرافقة لعملية الابداع، في حر الك نحو المستقبل. الـ ـ ـ لم تتمثل الاسلوبية والاساليب الى نموذج قيمي أو أخلافي محدد، من حيث ان النتاج الفني له عو المه وصوره

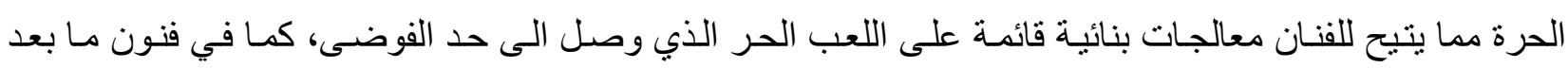
الحداثة التي اذابت الحدود بين المقدس والمدنس. با - إثتملت فنون ما بعد الحداثة على نتاجـات فجـة لا تمتلك مقومـات أسلوبية جر اء نزوعها للتشتيت و التفكيك، وان إمتلكت الاسلوب، فأنه لا يحمل صفة الاصالة و التوصيف الجمالي.

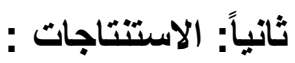
في ضوء ما أسفر عنه البحث من نتائج، نستنتج الآتي: ـ ـ ان تعاطي التشكيل الفني مع النظرية الاسلوبية، يعد الاكثر تجانساً وتلاقياً من النظريات الاخرى كالبنيويـة

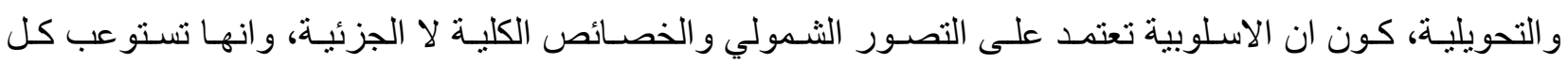
الكيفيات و الاتجاهات الفنية.

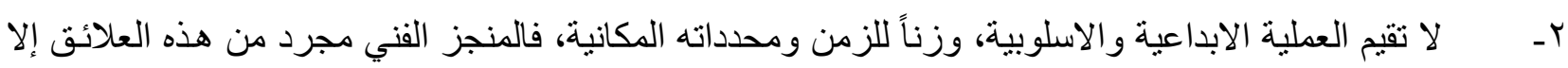

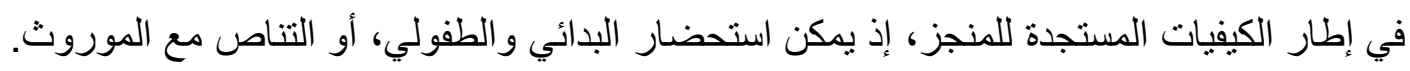
r- تتعزز الاسلوبية في التنوع الاسلوبي، وهذا ما يوثق صلة الاسلوبية بالتشكيل الفني للحداثة ومـا بعد الحداثة، اكثر من فتر ات الفن السابقة. ع - يعد الاسـلوب بمثابـة الهويـة للفنـان، فالاسلوب خلاصـة لكينونته الثخصية ومنظومتـه الفكريـة والاجتماعيـة 


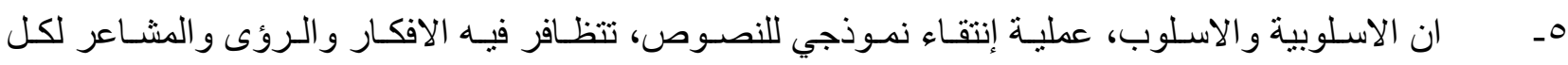
أطر اف المنجز، يسفر عن معالجات بنائية وادائية وتقنية، مما يجعل للنص خصوصيته الثشاملة.

ثُالثاً: التوصيات في ضوء ما اسفر عنه البحث من نتائج واستنتاجات، نوصي بالآتي: ا - تضمين المو اد الدراسية النقدية، النظرية الاسلوبية و آلياتها في القراءة واختلافها عن النظريات النقدية الاخرى r- تفعيل عمليات الترحيل للنظريات النقدية الى الفن كمجال عملي تطبيقي لتلك النظريات.

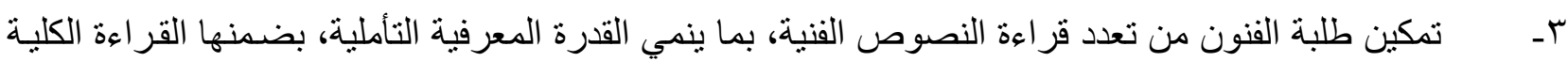
و الثمولية التي تتميز بها الاسلوبية. رابعاً: المقترحات

إستكمالاً للفائدة، نتترح اجر اء الدراسات الاتية:

1 - إثكاليات قر اءة النصوص الفنية بين الاسلوبية والبنيوية. r- أثر المرجعيات الفكرية في تكوين الاساليب الفنية. r- الخصائص الاسلوبية لفن ما بعد الحداثة.

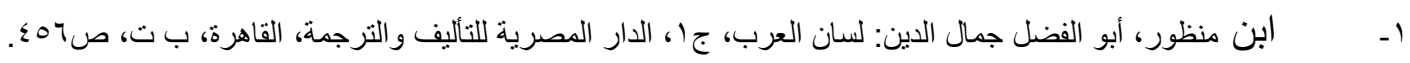

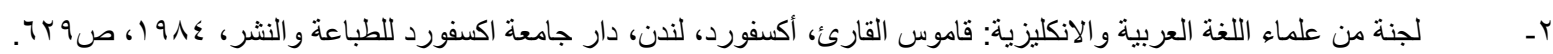

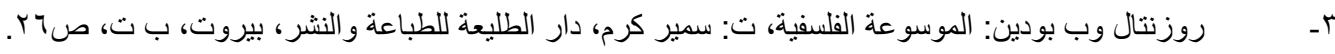

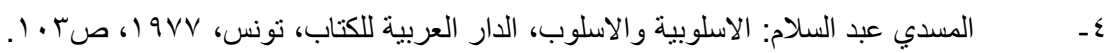

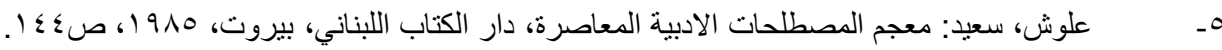

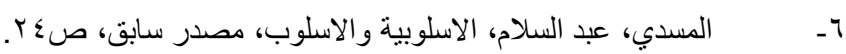

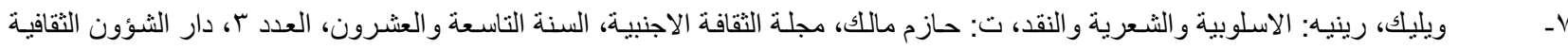

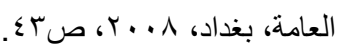

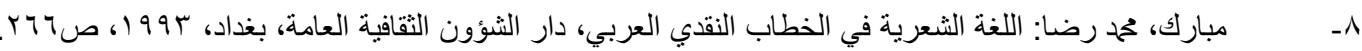

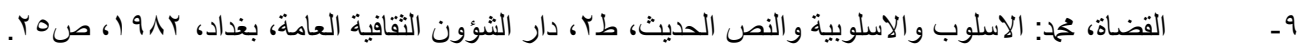

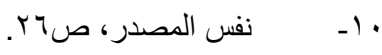

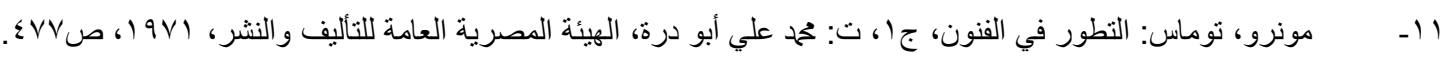

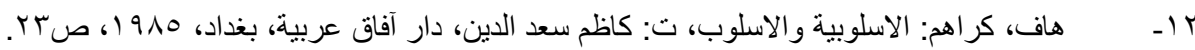

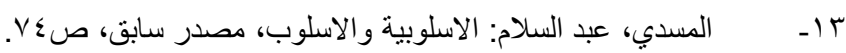

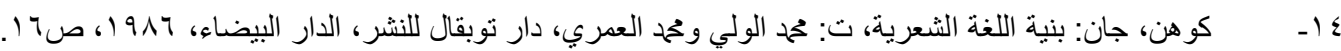

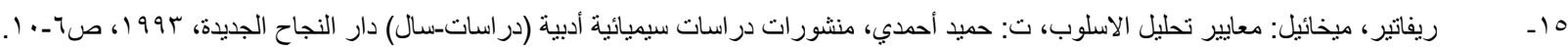

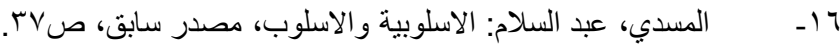

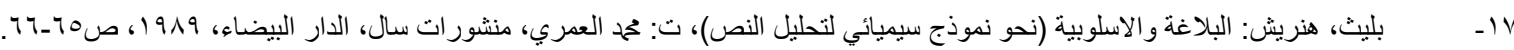

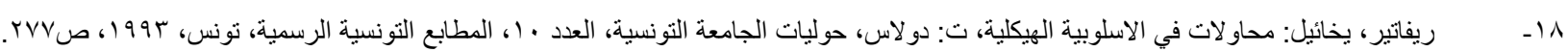

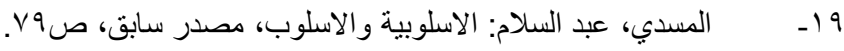

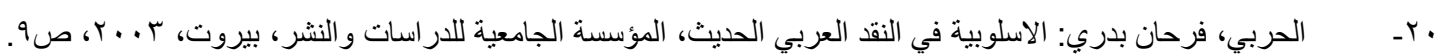

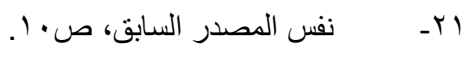




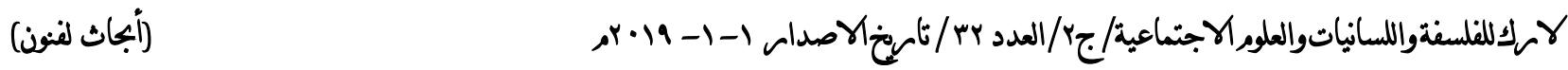

$$
\begin{aligned}
& \text { r T- كوهن، جان: بنية اللغة الثعرية، ت: احمد درويش، مكتبة الزهراء، القاهرة، ب ت، ص71. }
\end{aligned}
$$

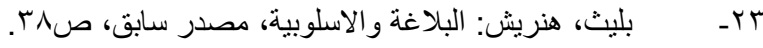

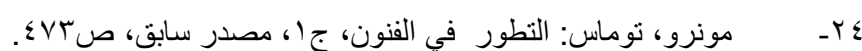

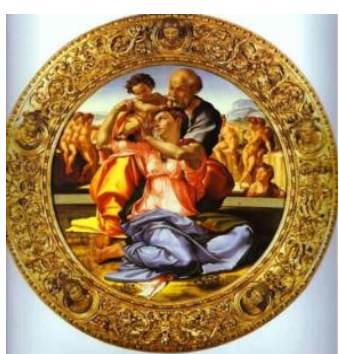

(الثكل "ا)
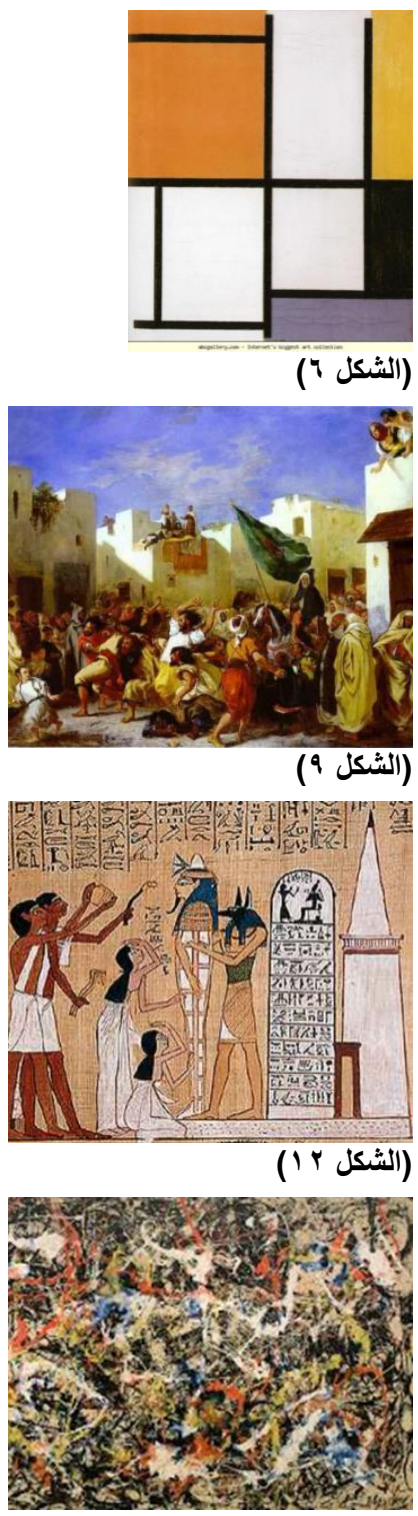

(الثكل 10 )
الملاحق (اشكال البحث)

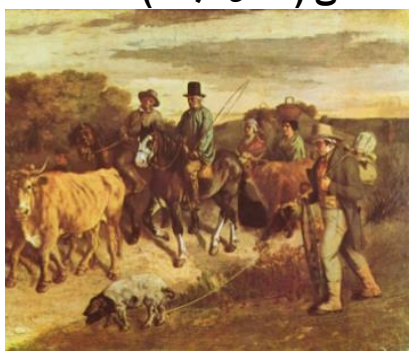

(الثكل r)
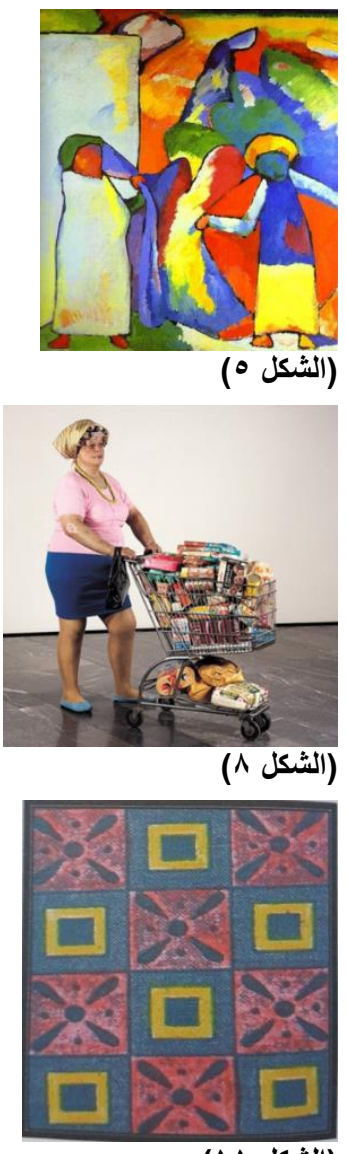

(الثكل (1)

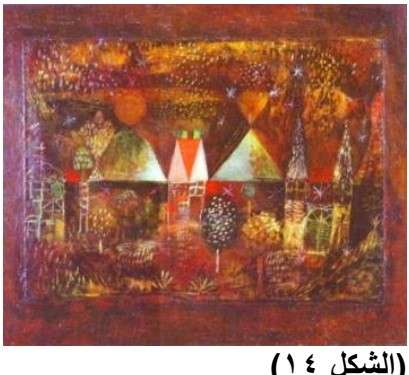

(الثكل \& 1)

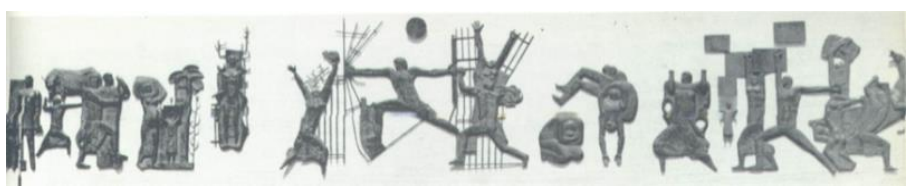

(الثكل 14)

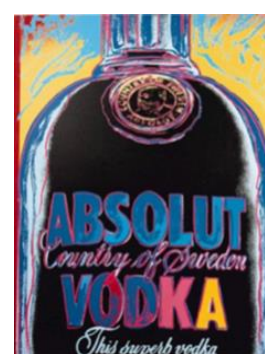

(الثكل (')
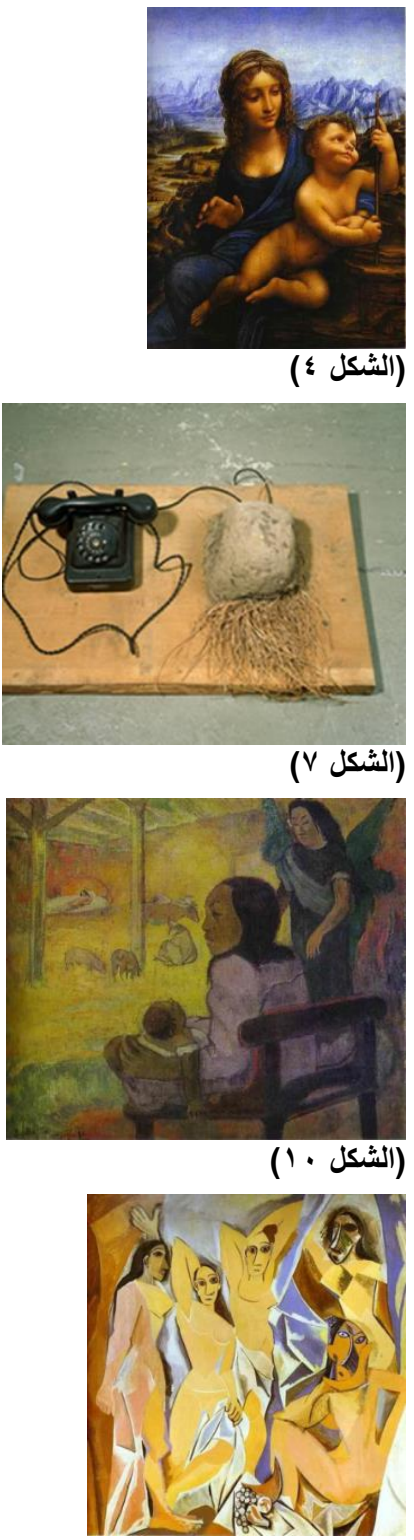

(الثكل r ( ) ( )

\section{$-Y \leqslant Y$.}

